Uncertainty Aversion in a Heterogeneous Agent Model of Foreign Exchange Rate Formation

Roman Kozhan and Mark Salmon 


\title{
Uncertainty Aversion in a Heterogeneous Agent Model of Foreign Exchange Rate Formation
}

\author{
Roman Kozhan* Mark Salmon \\ Financial Econometrics Research Centre \\ Warwick Business School
}

\begin{abstract}
This paper provides what we believe to be the first empirical test of whether investors in the foreign exchange market are uncertainty averse. We do this using a heterogeneous agents model in which fundamentalist and chartist beliefs of the exchange rate co-exist and are allowed to be either uncertainty neutral or uncertainty averse. Uncertainty aversion is modelled using the maxmin expected utility approach. We find significant evidence of uncertainty aversion in the FX market where in particular fundamentalists are found to be largely uncertainty neutral while chartists are mainly uncertainty averse. Inclusion of uncertainty averse agents significantly improves the performance of the model.
\end{abstract}

Key words: uncertainty aversion, exchange rate formation, heterogeneous agents.

JEL Classification: C12, C15, C63, D81, F31

*Address for correspondence: Roman Kozhan and Mark Salmon, FERC, Warwick Business School, The University of Warwick, Scarman Road, Coventry, CV4 7AL, UK; tel: +44 247652 4118; fax: +44 247652 4167; e-mails: Roman.Kozhan@wbs.ac.uk, Mark.Salmon@wbs.ac.uk 


\section{Introduction}

Foreign exchange theory and modelling has been in a state of turmoil since Meese and Rogoff (1983) demonstrated that standard theoretical models, of that time, could not outperform a random walk in out-of-sample prediction. The problem is that a random walk can only represent an efficient price if the expected equilibrium exchange rate were to be constant and for many reasons, in a risk averse world, this is an unacceptable position to take. Theory implies that the expected equilibrium rate varies over time to reflect, amongst other factors, time varying risk premia which should imply a degree of predictability. Standard foreign exchange models developed within the rational representative agent framework appear therefore to be dominated by a simple random walk model that is itself seen to be invalid.

Despite considerable research in the intervening 25 years no consensus theoretical paradigm has been developed to resolve the paradox raised by Meese and Rogoff. A recent detailed analysis by Della Corte, Sarno and Tsiakas (2008) concludes, following a Bayesian Model Averaging exercise, that fundamentals are important but a variety of different models may be relevant to explain behaviour in foreign exchange markets. We believe a new theoretical paradigm may be needed to explain these results - one which removes the representative agent paradigm and addresses uncertainty as opposed to risk in financial markets. This paper represents the first attempts to bring these two concepts to bear in order to explain observed movements in foreign exchange rates.

Finance theory has traditionally been based on an analysis of Risk, measured using some aspect of a distribution which is assumed to be unique and characterises returns. However a growing body of research has argued that one reason why the standard model, based on expected utility theory, fails to explain many "anomalies" and stylised facts observed across financial markets may be because agents in these markets face Uncertainty as opposed to Risk, as originally suggested by Knight (1921) and Keynes (1921). Bewley (2002) makes the distinction between Risk and Uncertainty in the following way; " a random variable is risky if its probability distribution is known, uncertain if its distribution is unknown". Market traders may simply not know which of several potential distributions to apply to evaluate an uncertain prospect or alternatively be faced with a situation in which they have no prior experience and hence have no distribution at all to call on to carry out 
their risk calculus. The required probabilities may therefore either be unknown or unmeasurable. As argued by Keynes and Knight the Uncertainty framework may in fact better represent decision making in financial markets than the classic Risk paradigm where agents are assumed not to doubt their models and in particular the associated probability distributions.

A number of authors have developed theories of decision-making under uncertainty including Schmeidler (1989), Gilboa and Schmeidler (1989), Quiggin (1982), and Epstein and Wang (1994), Uppal and Wang (2003), Maenhout (2004) and Hansen and Sargent (2007) among others have applied related ideas of robust decision making to a variety of issues in Economics and Finance. Maccheroni, Marinacci and Rustichini (2006) (see also Maccheroni, Marinacci, Rustichini and Taboga (2008)) have recently developed Variational Preferences that unify a preference for robustness and the multiple prior preferences of Gilboa and Schmeidler into a single framework and developed an Uncertainty based CAPM. The approach taken in these papers has been shown, often through simulation, to have the potential to successfully explain a number of anomalies seen in decision-making, such as the Ellsberg and Allais paradoxes as well as to provide explanations for the Equity Premium and Home Bias puzzles. While the theoretical basis for decision-making under uncertainty has become relatively well developed, there is a clear lack of hard empirical evidence justifying the use of this alternative framework as a basis for explaining behaviour in financial markets. In other words, the question of whether people are uncertainty averse or have non-additive preferences in reality has not yet been resolved empirically $!^{1}$ In this paper we provide what we believe to be the first formal empirical test of uncertainty aversion within traders in an FX market.

One obstacle is that virtually all models of decision-making under uncertainty in finance and foreign exchange rate theory are representative agent models and this seems in direct contrast with simple observation of all financial markets which

\footnotetext{
${ }^{1}$ There have been a number of studies (see for instance Ellsberg (1961), Mangelsdorf and Weber (1994), Wakker (2001)) which provide empirical evidence that humans are more uncertainty averse than uncertainty loving. However, the data used in these studies were collected either from questionnaires or laboratory experiments. Answering a questionnaire or acting in an artificial experiment may be quite different from taking real decisions in a market which may influence an individual's future well being. The issue of whether the realised prices are in fact influenced by uncertainty aversion of traders to our knowledge has not been addressed in the existing literature.
} 
are in fact populated by heterogeneous agents. So first, we develop a model of the FX market in which we allow fundamentalist and chartist beliefs of the exchange rate to co-exist and where traders are allowed to be either uncertainty neutral or uncertainty averse. As a basis for our model we draw on and extend existing models of the foreign exchange market developed in Brock and Hommes (1998), De Grauwe and Grimaldi (2006), Kirman, Ricciotti and Topol (2006), Boswijk, Hommes and Manzan (2007). This approach allows us to form endogenous demand and supply through the interaction of the different types of agents in the market. The realised exchange rate is then determined from the market clearing condition. Heterogeneity within agents' beliefs, whether fundamentalist or chartist, is captured by allowing for different ways the expectations of future prices are formed. Every agent in the model - either fundamentalist or chartist - may be uncertainty neutral or uncertainty averse.

As mentioned above, there are several ways to model decision making under uncertainty and in this paper we use probably the most simple - maxmin expected utility (also known as the multiple priors model or worst-case scenario model) of Gilboa and Schmeidler (1989). This approach has been used in several different asset allocation models, see Andersen, Hansen and Sargent (2000), Chen and Epstein (2002), Uppal and Wang (2003), Zhao, Haussmann and Ziemba (2003), Garlappi, Uppal and Wang (2004). The approach allows for a variety of different methods to construct the multiple prior set which then reflects the degree of uncertainty or the range of potential models that might explain behaviour in foreign exchange markets. The "extreme" event in this set may in fact be local to the null model depending on how the prior set is drawn up. We assume that the investor is then faced with forming expectations regarding future exchange rates and considers the worst outcome within this set of models or effectively some interval, where the width of the interval is a subjective choice of the investor and hence is able to capture different degrees of uncertainty aversion. Using the Unscented Kalman Filter (UKF) and nonlinear least squares methods we then estimate the model and test whether this critical parameter (the width) is significantly different from zero and hence whether uncertainty aversion exists in the foreign exchange market.

The paper is organised as follows. The next section provides a description of the model. In Section 2 we outline the Unscented Kalman filter, used here as a method of state estimation and then parameter estimation by the nonlinear least squares. 
Section 3 contains the estimation results and model evaluation including specification tests relating to the model. The discussion and interpretation of the results is given in Section 4. Finally we provide some concluding remarks in Section 5 .

\section{Heterogeneous Agent Model}

We assume that there are two currencies - domestic and foreign which are traded on the foreign exchange market. Denote by $s_{t}$ the foreign exchange rate at time $t-$ the price of one unit of foreign currency in units of domestic currency. There are $N$ investors competing by trading in the market. Let $\rho_{t}$ be the interest rate relevant to the foreign currency and $r_{t}$ be the interest rate for the domestic country over the period $t$.

An agent's wealth at time $t$ is determined by his trading activity and is equal to

$$
W_{t}=\left(1+r_{t-1}\right) d_{t-1}+s_{t}\left(1+\rho_{t-1}\right) f_{t-1}
$$

where $d_{t}$ and $f_{t}$ denote trader's demands on domestic and foreign currency respectively held at time $t$. The individual's demands must satisfy the budget constraint $W_{t}=d_{t}+s_{t} f_{t}$ at each point of time.

There are two types of investor: fundamentalists and what we will call chartists but really these are defined by the tools they use to form expectations. The former believe that there exists an equilibrium price (fundamental value) $\bar{s}_{t}$ towards which the exchange rate will always move. More precisely, their expectation of the change in the exchange rate is proportional to the observed difference between the fundamental value and the previous level of the exchange rate and is expressed by the formula

$$
E_{t}\left(s_{t+1} \mid F\right)=s_{t-1}+v\left(\bar{s}_{t}-s_{t-1}\right) \text { with } 0 \leq v \leq 1
$$

where expectations are calculated conditional on the information available at time $t$. We discuss below in Subsection 1.4 how the value $\bar{s}$ is determined.

We assume chartists use a simple long-short moving average rule in order to predict a future deviation from its past level. Their exchange rate forecast is then given by

$$
E_{t}\left(s_{t+1} \mid C\right)=s_{t-1}+h\left(\frac{1}{M_{s}} \sum_{i=1}^{M_{s}} s_{t-i}-\frac{1}{M_{l}} \sum_{i=1}^{M_{l}} s_{t-i}\right) \text { with } h>0,
$$


where $M_{s}$ and $M_{l}$ are the lengths of the short and long moving average windows respectively.

There is substantial evidence that foreign exchange markets are populated by both these beliefs in one form or another. The surveys by Taylor and Allen (1992) and Cheung, Chinn and Marsh (2004) show that chartist methods are widely used in financial intitutions $2^{2}$ along with fundamentals models, inviably based on interest rate parity conditions. Our particular choice of models for forming expectations just represent simple examples and more complex and potentially realistic models could be considered, in particular to extend the simple long-short moving average rule we have employed to represent chartist beliefs.

The information available to both types of trader at time $t$ includes past levels of the exchange rate and past and present values of the fundamental variables, interest rates in our case. We do not allow agents to observe the contemporaneous equilibrium exchange rate since this is naturally a latent variable in the market as opposed to the rate realised at the last transaction. A similar assumption is also used by Hellwig (1982), Blume, Easley and OHara (1994), Boswijk et al. (2007) etc.

For analytic tractability, following Brock and Hommes (1998), Boswijk et al. (2007) we assume that all investors have homogeneous expectations about the conditional second moment of the exchange rate $E_{t}\left(s_{t}^{2} \mid I\right)=E_{t}\left(s_{t}^{2}\right), I=F, C$.

\subsection{Demand functions}

We identify four different individual demand functions which determine the market clearing exchange rate. In particular, $f_{t}^{n}(I)$ and $f_{t}^{u}(I), I=F, C$ denote individual demands for the foreign currency by investors (uncertainty neutral and uncertainty averse, denoted by subscripts $n$ and $u$ respectively). The variable $I$ indicates the individual's beliefs as being chartist or fundamentalist at time $t$ based on past information. (Hereafter we omit a variable $I$ for notational convenience in statements which are true for both types of agent and where it does not cause a misunderstanding).

\footnotetext{
${ }^{2}$ Including Central Banks as personal conversation within the Bank of England have shown us in preparing this paper.
} 


\section{Uncertainty neutral agents}

Agents' risk preferences are characterised by a quadratic utility function $U(x)=$ $x-\gamma x^{2}$, where we assume that the risk-aversion coefficient $\gamma$ is the same for all traders. Let an uncertainty neutral agent decide to hold $f_{t}^{n}$ foreign currency units at time $t$. Then, any uncertainty-neutral investor maximises the quadratic expected utility function of the next-period wealth

$$
E_{t}\left(U\left(W_{t+1}^{n}\right) \mid I\right)=E\left(W_{t+1}^{n} \mid I\right)-\gamma E\left(\left(W_{t+1}^{n}\right)^{2} \mid I\right) \underset{f_{t}^{n}}{\rightarrow} \max .
$$

The agent's wealth at the next period $t+1$ is given by

$$
W_{t+1}^{n}=\left(1+r_{t}\right)\left(W_{t}^{n}-s_{t} f_{t}^{n}\right)+s_{t+1}\left(1+\rho_{t}\right) f_{t}^{n} .
$$

Maximising the expected utility of the next period's wealth with respect to $f_{t}^{i, n}$, domestic agents are able to determine their optimal trade, which is given in the following theorem.

Lemma 1.1. Given exchange rate level $s_{t}$ the optimal trade of an uncertainty neutral agent is to hold $f_{t}^{n}$ units of foreign currency, where

$$
f_{t}^{n}=\frac{E_{t}\left(s_{t+1} \mid I\right)\left(1+\rho_{t}\right)-s_{t}\left(1+r_{t}\right)}{2 \gamma E_{t}\left(s_{t+1}^{2} \mid I\right)\left(1+\rho_{t}\right)^{2}} .
$$

See Appendix for the proof.

\section{Uncertainty averse agents}

Uncertainty averse agents maximise their maxmin quadratic expected utility function of future wealth (see Gilboa and Schmeidler (1989), Garlappi et al. (2004)). Their preferences are expressed by the set of possible future expected values of the exchange rate determined by a (symmetric) bandwidth $\delta_{I}$ around the base or uncertainty neutral expectation. That is, an uncertainty averse domestic agent assumes that the future exchange rate takes its value in the interval $\left[E_{t}\left(s_{t+1} \mid I\right)-\right.$ $\left.\delta_{I}, E_{t}\left(s_{t+1} \mid I\right)+\delta_{I}\right], I=F, C$. The maximisation problem of such an agent can be written as follows:

$$
E_{t}\left(U\left(W_{t+1}^{u}\right) \mid I\right)=\min _{s \in\left[E_{t}\left(s_{t+1} \mid I\right)-\delta_{I}, E_{t}\left(s_{t+1} \mid I\right)+\delta_{I}\right]} E_{t}\left(W_{t+1}^{u}(s) \mid I\right)-\gamma E_{t}\left(\left(W_{t+1}^{u}(s)\right)^{2} \mid I\right) \underset{f_{t}^{u}}{\rightarrow} \max
$$

with respect to budget constraint

$$
W_{t+1}^{u}\left(s_{t+1}\right)=\left(1+r_{t}\right)\left(W_{t}^{u}-s_{t} f_{t}^{u}\right)+s_{t+1}\left(1+\rho_{t}\right) f_{t}^{u} .
$$


Let us denote

$$
\begin{aligned}
& C(I)=\frac{E_{t}\left(s_{t+1} \mid I\right)\left(1+\rho_{t}\right)-s_{t}\left(1+r_{t}\right)}{2 \gamma E_{t}\left(s_{t+1}^{2} \mid I\right)\left(1+\rho_{t}\right)^{2}}, \\
& C_{\max }(I)=\frac{\left(E_{t}\left(s_{t+1} \mid I\right)+\delta_{I}\right)\left(1+\rho_{t}\right)-s_{t}\left(1+r_{t}\right)}{2 \gamma E_{t}\left(s_{t+1}^{2} \mid I\right)\left(1+\rho_{t}\right)^{2}}, \\
& C_{\min }(I)=\frac{\left(E_{t}\left(s_{t+1} \mid I\right)-\delta_{I}\right)\left(1+\rho_{t}\right)-s_{t}\left(1+r_{t}\right)}{2 \gamma E_{t}\left(s_{t+1}^{2} \mid I\right)\left(1+\rho_{t}\right)^{2}} .
\end{aligned}
$$

Lemma 1.2. Given the level of exchange rate $s_{t}$ the optimal strategy of an uncertainty averse agent is to hold $f_{t}^{u}$ units of foreign currency, where

$$
f_{t}^{u}=\left\{\begin{array}{lll}
C_{\min }(I) & \text { if } \quad s_{t}<E_{t}\left(s_{t+1} \mid I\right)-\delta_{I}, \\
0 & \text { if } \quad E_{t}\left(s_{t+1} \mid I\right)-\delta_{I} \leq s_{t} \leq E_{t}\left(s_{t+1} \mid I\right)+\delta_{I}, \\
C_{\max }(I) & \text { if } \quad E_{t}\left(s_{t+1} \mid I\right)+\delta_{I}<s_{t} .
\end{array}\right.
$$

See the Appendix for the proof.

\subsection{Learning through social interaction}

Consistent with observed behaviour in the markets investors may change the way they make their decisions at every period of time, as discussed in Menkhoff and Taylor (2007). They may switch the way they form expectations about future exchange rates (become fundamentalists or chartists) and also their reaction to uncertainty in the market can change. The learning mechanism of agents is similar to some extent to case-based reasoning and is based on the cumulative gain of particular groups of agents and a comparison with the past experience of other investors. This sort of updating is implemented in heterogeneous agents models by, inter alia, Kirman (1993), Kirman et al. (2006), De Grauwe and Grimaldi (2006), Boswijk et al. (2007).

At the beginning of period t agents compare the realised utilities of the different strategies and invest into those which perform better. To be more precise, each trader chooses a strategy in a probabilistic manner where the probability of choosing a strategy depends on its past performance. According to this model the probability of an investor becoming a fundamentalist at time $t$ can be calculated as

$$
P_{t+1}(F)=\frac{e^{\beta G_{t}(F)}}{e^{\beta G_{t}(F)}+e^{\beta G_{t}(C)}},
$$

where $G_{t}(F)$ and $G_{t}(C)$ are discounted sums of the one-period utilities of the fundamentalists and chartists respectively given that both types of agent had the same initial level of wealth. That is,

$$
G_{t}(I)=\sum_{j=1}^{m} \omega^{j-1} U\left(g_{t-j+1}(I)\right)
$$


with $g_{t}(I)=\left(1+r_{t-1}\right)\left(W_{t-1}-s_{t-1} f_{t-1}^{n}(I)\right)+s_{t}\left(1+\rho_{t-1}\right) f_{t-1}^{n}(I)$. The parameter $\beta$ here is called the intensity of choice (see Boswijk et al. (2007)) and $\omega$ plays the role of a discount factor.

Simultaneously with changing the method of expectation formation, a trader can change his reaction to the level of uncertainty present in the market. Sentiment indicators are frequently found to be significant in explaining asset returns which reflects the time varying nature of uncertainty in markets. If, based on the past performance an uncertainty averse strategy appears better in terms of utility than being uncertainty neutral, traders will become more careful and less aggressive as specified by the maxmin model. If the information available in the market is treated as "certain", then agents will be more willing to choose a simple expected utility strategy. Under severe uncertainty the maxmin strategy can be as bad as a "do nothing" strategy while under mild uncertainty it will earn some positive utility and will be less sensitive to bad outcomes. In the same way the probability of an investor becoming uncertainty neutral is obtained from the formula

$$
P_{t+1}(n, I)=\frac{e^{\beta G_{t}^{n}(I)}}{e^{\beta G_{t}^{n}(I)}+e^{\beta G_{t}^{u}(I)}},
$$

where $G_{t}^{n}(I)$ and $G_{t}^{u}(I)$ are discounted sums of the one-period utilities of corresponding uncertainty neutral and uncertainty averse strategies respectively.

This learning mechanism ensures that strategies with higher realised utility in the recent past become more attractive to agents. In this way, traders do not systematically make mistakes but learn about the strategy with the highest current performance.

\subsection{The Market Clearing Exchange Rate}

In order to be able to define the aggregate demand functions we denote the proportion of fundamentalists in the market by $x_{t}$ and let $y_{t}^{F}$ and $y_{t}^{C}$ define the proportions of uncertainty neutral investors among fundamentalists and chartists respectively. These proportions will change with time according to the probabilities specified above.

As we can see each individual demand function is a function of the expected value of the level of the foreign exchange rate $s_{t}$. Depending on past information an investor decides how to build his expectation: based on fundamental variables or 
by inferring structure from historical exchange rate patterns (or in other words - be fundamentalist or chartist). Let us denote by $\Phi_{t}\left(s_{t}\right)$ the aggregate demand function at time $t$.

These demand functions can be presented in the form

$$
\Phi_{t}\left(s_{t}\right)=N\left(x_{t} y_{t}^{F} f_{t}^{i, n}(F)+x_{t}\left(1-y_{t}^{F}\right) f_{t}^{i, u}(F)+\left(1-x_{t}\right) y_{t}^{C} f_{t}^{i, n}(C)+\left(1-x_{t}\right)\left(1-y_{t}^{C}\right) f_{t}^{i, u}(C)\right) .
$$

The market clearing exchange rate $s_{t}^{*}$ is then a solution of the market clearing equation

$$
\Phi_{t}\left(s_{t}^{*}\right)=0
$$

that is, the aggregate demand must be equal to aggregate supply which is held at 0 for simplicity. We denote the pricing function by $\tilde{\mathbf{f}}\left(\mathcal{F}_{t}\right)=\Phi_{t}^{-1}(0)$, where $\mathcal{F}_{t}$ is the information available it time $t$. If the function $\Phi$ is not invertible, we can treat $\tilde{\mathbf{f}}$ as a generalised inverse considering the solution that minimises $\Phi$ (the distance minimising solution).

\subsection{The Fundamental Exchange Rate}

Fundamentalists are assumed to form their beliefs about the latent fundamental equilibrium exchange rate, $\bar{s}_{t}$, based on the Uncovered Interest Parity Condition. They believe that $\log \left(\bar{s}_{t}\right)=\log \left(\bar{s}_{t-1}\right)+\log \left(r_{t-1}\right)-\log \left(\rho_{t-1}\right)$. Notice that UIP is only used to determine the latent equilibrium exchange rate since it is well known that market rates fail to satisfy the UIP condition. In fact, our model could provide one explanation for the existence of the carry trade through the presence of uncertainty averse heterogeneous agents in the market. Since the fundamental exchange rate is unobservable, fundamentalists are assumed to use a state space estimation method to form their estimation of $\bar{s}$. As in the Standard Kalman Filter they form prior beliefs and use a Bayesian rule to update these beliefs but because of out model is nonlinear we have to move beyond the simple Kalman Filter. Fundamentalists are rational in the way they take into account both fundamental information and the presence of chartists in the market. They use this information to derive the posterior distribution of the fundamental price from which the optimal state estimate can be derived. This estimate is then used together with realised exchange rates when forming their expectations of the market rate through equation (1.1) and their 
demands which in turn to determine the market rate along with chartist demands. Assuming a gaussian error term, the expression for the fundamental price $\overline{s_{t}}$ will be

$$
\log \left(\bar{s}_{t}\right)=\log \left(\bar{s}_{t-1}\right)+\log \left(r_{t-1}\right)-\log \left(\rho_{t-1}\right)+\sigma_{\bar{s}} \xi_{t}
$$

with $\xi_{t} \sim N(0,1)$. In the absence of chartists, fundamentalist traders would drive the exchange rate to the fundamental price and it would coincide with the rational expectations equilibrium. Hereafter we use the notation $\bar{s}_{t}$ also to denote the estimate of the fundamental rate where it does not lead to confusion.

Chartists are boundedly rational since while recognising the presence of fundamentalists they choose not to take available fundamental information into account $3^{3}$ They simply believe in their chartist rule and use it to extrapolate an exchange rate forecast which therefore systematically deviates from the fundamental exchange rate.

The timing of the model is the following. Traders, based on the recent performance of different strategies decide upon their type and their attitude to uncertainty. Based on these choices the proportion of agent types is determined. At that time, those traders who decided to use the chartist strategy form their expectation of future exchange rate extrapolating past prices and compute their demand function through the maximisation problem (1.3). Fundamentalists update their beliefs about the fundamental rate taking into account current interest rates and form their expectations and demand functions. The market then clears at the market clearing price level at the end of the day which provides the model's output for the level of the exchange rate from the solution of equation 1.6 .

\section{Estimation}

We now describe the estimation of the latent fundamental rate and the parameters of the model. Given that the model is highly nonlinear, the Bayesian estimation of the model is performed using an Unscented Kalman Filter, which is described in the following subsection. Having then estimated the fundamental price we use nonlinear least squares to estimate the parameters of the model.

\footnotetext{
${ }^{3}$ This again reflects reality since chartist methods are typically used in short run decision making (i.e., intraday) when no new fundamental information is available.
} 


\subsection{Unscented Kalman Filter}

The Unscented Kalman Filter (UKF hereafter) allows us to deal directly with the nonlinearities present in the model without approximation or linearisation using a form of Particle Filter and hence provides a much more accurate estimate of the evolution of the nonlinear stochastic process than the standard Kalman Filter or the Extended Kalman Filter. This algorithm was proposed by Julier and Uhlmann (2004) and allows us to solve the problem of nonlinear filtering using nonlinear transformations of Gaussian distributions. We give a brief sketch of the UKF algorithm below. A more extensive description can be found in Julier and Uhlmann (2004), Van der Merwe (1998).

We are interested in estimating a nonlinear model of the form

$$
\begin{array}{r}
\mathbf{y}_{t}=\mathbf{f}\left(\mathbf{u}_{t}, \mathbf{x}_{t}, \mathbf{n}_{t}\right) \\
\mathbf{x}_{t}=\mathbf{h}\left(\mathbf{x}_{t-1}, \mathbf{u}_{t}, \mathbf{w}_{t}\right),
\end{array}
$$

where $\mathbf{y}_{t} \in \mathbb{R}^{n_{y}}$ denotes the observable output time series, in our case the level of the market clearing exchange rate, $\mathbf{u}_{t} \in \mathbb{R}^{n_{u}}$ the input data (interest rates and past exchange rates), $\mathbf{x}_{t} \in \mathbb{R}^{n_{x}}$ the unobserved state of the system, in our case the fundamental rate, $\mathbf{w}_{t} \in \mathbb{R}^{n_{w}}$ the process noise and $\mathbf{n}_{t} \in \mathbb{R}^{n_{n}}$ the measurement noise. The functions $\mathbf{f}$ and $\mathbf{h}$ are said to represent the state measurement and transition models respectively; (2.1) represents the solution to (1.6) for the observed market clearing exchange rate and 2.2 corresponds to the UIP condition determining the fundamental exchange rate (1.7).

The unscented transformation method directly evaluates the nonlinearities in $\mathbf{f}$ and $\mathbf{h}$ through a sequential monte carlo simulation and directly calculates the first two moments of $\mathbf{x}$ and $\mathbf{y}$ from the nonlinear system itself. Let us denote by $\mathbf{x}_{t}^{a}=\left[\mathbf{x}_{t}^{T} \mathbf{w}_{t}^{T} \mathbf{n}_{t}^{T}\right]^{T}$ and by $\mathbf{x}_{t \mid t}^{a}$ and $\mathbf{P}_{t \mid t}^{a}$ the mean and covariance of $\mathbf{x}^{a}$ at time $t$. In order to provide a transformation, a set of $2 n_{a}+1$ weighted samples of sigma points $\mathcal{S}_{i}=\left\{\mathbf{W}_{i}, \mathcal{X}_{i}\right\}, n_{a}=n_{x}+n_{w}+n_{v}$ are chosen so that they completely capture the true mean and covariance of the prior random variable $\mathbf{x}_{t}^{a}$. This may be carried out 
as follows:

$$
\begin{aligned}
& \mathcal{X}_{0}^{a}=\mathbf{x}_{t \mid t}^{a} \\
& \mathcal{X}_{i, t \mid t}^{a}=\mathbf{x}_{t \mid t}^{a}+\left(\sqrt{\left(n_{a}+\lambda\right) \mathbf{P}_{t \mid t}^{a}}\right)_{i}, \quad i=1, \ldots, n_{x} \\
& \mathcal{X}_{i, t \mid t}^{a}=\mathbf{x}_{t \mid t}^{a}-\left(\sqrt{\left(n_{a}+\lambda\right) \mathbf{P}_{t \mid t}^{a}}\right)_{i}, \quad i=n_{x}+1, \ldots, 2 n_{x} \\
& W_{0}^{(m)}=\frac{\lambda}{n_{a}+\lambda} \\
& W_{0}^{(c)}=\frac{\lambda}{n_{a}+\lambda}+\left(1-\alpha^{2}+\beta\right) \\
& W_{i}^{(m)}=W_{i}^{(c)}=\frac{1}{2\left(n_{x}+\lambda\right)}
\end{aligned}
$$

with $\lambda=\alpha^{2}\left(n_{a}+\kappa\right)-n_{a}, \kappa \geq 0,0 \leq \alpha \leq 1$ and $\beta \geq 0$. Here $\left(\sqrt{\left(n_{a}+\lambda\right) \mathbf{P}_{t \mid t}^{a}}\right)_{i}$ denotes the $i$ th column of the matrix square root of $\left(n_{a}+\lambda\right) \mathbf{P}_{t \mid t}^{a}$. In our implementation we set $\kappa=2, \alpha=0.9, \beta=2$.

The prediction step of the UKF can be sketched in the following way.

$$
\begin{aligned}
\mathcal{X}_{t+1 \mid t}^{x} & =\mathbf{h}\left(\mathcal{X}_{t \mid t}^{x}, \mathcal{X}_{t \mid t}^{w}\right) \\
\mathbf{x}_{t+1 \mid t} & =\sum_{i=1}^{2 n_{a}+1} W_{i}^{(m)} \mathcal{X}_{i, t+1 \mid t}^{x} \\
\mathbf{P}_{t+1 \mid t} & =\sum_{i=1}^{2 n_{a}+1} W_{i}^{(c)}\left[\mathcal{X}_{i, t \mid t+1}^{x}-\mathbf{x}_{t+1 \mid t}\right]\left[\mathcal{X}_{i, t \mid t+1}^{x}-\mathbf{x}_{t+1 \mid t}\right]^{T} \\
\mathcal{Y}_{t+1 \mid t} & =\mathbf{f}\left(\mathcal{X}_{t+1 \mid t}^{x}, \mathcal{X}_{t \mid t}^{n}\right) \\
\mathbf{y}_{t+1 \mid t} & =\sum_{i=1}^{2 n_{a}+1} W_{i}^{(m)} \mathcal{Y}_{i, t+1 \mid t} .
\end{aligned}
$$

The measurement update equations are as follows:

$$
\begin{aligned}
& \mathbf{P}_{\mathbf{x y}}=\sum_{i=1}^{2 n_{a}+1} W_{i}^{(c)}\left[\mathcal{X}_{i, t \mid t+1}^{x}-\mathbf{x}_{t+1 \mid t}\right]\left[\mathcal{Y}_{i, t \mid t+1}-\mathbf{y}_{t+1 \mid t}\right]^{T} \\
& \mathbf{P}_{\mathbf{y y}}=\sum_{i=1}^{2 n_{a}+1} W_{i}^{(c)}\left[\mathcal{Y}_{i, t \mid t+1}-\mathbf{y}_{t+1 \mid t}\right]\left[\mathcal{Y}_{i, t \mid t+1}-\mathbf{y}_{t+1 \mid t}\right]^{T} \\
& \mathbf{K}_{t+1}=\mathbf{P}_{\mathbf{x y}} \mathbf{P}_{\mathbf{y y}}^{-1} \\
& \mathbf{x}_{t+1 \mid t+1}=\mathbf{x}_{t+1 \mid t}+\mathbf{K}_{t+1}\left(\mathbf{y}_{t}-\mathbf{y}_{t+1 \mid t}\right) \\
& \mathbf{P}_{t+1 \mid t+1}=\mathbf{P}_{t+1 \mid t}-\mathbf{K}_{t+1} \mathbf{P}_{\mathbf{y y}} \mathbf{K}_{t+1}^{T} .
\end{aligned}
$$

\subsection{Nonlinear Least Squares (NLS) Estimation}

The UKF method allows us to write the model in the form

$$
\mathbf{y}_{t}=\mathbf{y}_{t+1 \mid t}(\theta)+\sigma \varepsilon_{t},
$$

where $\mathbf{y}_{t}$ is the observed time series (exchange rate levels in our case) and $\varepsilon_{t}$ are independent identically distributed random variables. The parameters $\theta \in \Theta$ of the 
model are then estimated (in a distribution free manner) by minimising the sum of squared errors

$$
S E=\frac{1}{N} \sum_{i=0}^{N}\left(\mathbf{y}_{t}-\mathbf{y}_{t+1 \mid t}(\theta)\right)^{2} \underset{\theta \in \Theta}{\longrightarrow} \min .
$$

The generalised nonlinear least squares estimates are asymptotically normally distributed

$$
\sqrt{N}(\hat{\theta}-\theta) \stackrel{a}{\sim} N(\mathbf{0}, \Omega)
$$

where $\Omega=A^{-1} B A^{-1}$ being White-Domowitz robust covariance matrix with

$$
\begin{aligned}
& A=2 N^{-1} \sum_{t=1}^{N} E\left(\nabla \mathbf{y}_{t}^{\prime} \nabla \mathbf{y}_{t}\right) \quad \text { and } \\
& B=4 N^{-1} \sum_{t=1}^{N} E\left(\varepsilon_{t}^{2} \nabla \mathbf{y}_{t}^{\prime} \nabla \mathbf{y}_{t}\right)+4 N^{-1} \sum_{\tau=1}^{N-1} \sum_{t=\tau+1}^{N} E\left(\varepsilon_{t} \varepsilon_{t-\tau}\left[\nabla \mathbf{y}_{t}^{\prime} \nabla \mathbf{y}_{t-\tau}+\nabla \mathbf{y}_{t-\tau}^{\prime} \nabla \mathbf{y}_{t}\right]\right)
\end{aligned}
$$

(see White and Domowitz (1984) for details).

\section{Empirical Results}

As we have said the function $\mathbf{f}$ in the measurement equation 2.1 solves the market clearing condition (1.6), that is, the measurement equation is $s_{t}=\tilde{\mathbf{f}}\left(\mathbf{u}_{\mathbf{t}}, \overline{\mathbf{s}}_{\mathbf{t}}\right)+\tilde{\varepsilon}_{\mathbf{t}}$. The function $\mathbf{h}$ in the state transition equation is in the form of the relation (1.7) with $\sigma_{\bar{s}} \xi_{t}$ being a noise. Inputs to the system are the interest rates $r_{t}$ and $\rho_{t}$ as well as the past realised prices $s_{t-j}, j=1, \ldots t-1$.

The proxies we use for the domestic and foreign risk-free rates $r$ and $\rho$ are the UK and US Interbank LIBOR overnight rates respectively and we use daily closing rates on the GBP/USD exchange rate over the period from 2 January 1997 till 30 June 2008, as shown in Figure 1.

For identification we need to tie down several parameters and since we are more interested in the degree of uncertainty aversion in traders we fix the risk aversion coefficient to be $\gamma=2$. Under the assumption of identical risk aversion for both types of investor, this coefficient in fact has no influence on the equilibrium prices in our model. The set of parameters remaining for estimation then consists of $\theta=\left\{\delta_{F}, \delta_{C}, \sigma_{\bar{s}}, v, h, \sigma, \beta\right\}$. As our main research question is to test for uncertainty 
aversion in traders, we are in particular interested in estimating the parameters $\delta_{F}$ and $\delta_{C}$ and testing if they are significantly different from zero. If these parameters are jointly insignificant this would imply that the observed spot rates are generated from a model where only uncertainty neutral agents interact. The variables $v$ and $h$ are adjustment coefficients in the expectations expressions for both types of agents. Heterogeneity in expectations is a main driver of the model and these parameters along with the intensity of choice parameter $\beta$ are the most important parameters for the benchmark model without uncertainty averse agents. The two remaining parameters $\sigma$ and $\sigma_{\bar{s}}$ need to be estimated as they are input values to the Unscented Kalman Filter.

The converged NLS estimates of the parameters, their standard deviations and the p-values of tests of significance are given in the following table.

$$
\text { [Insert Table 1 here] }
$$

Based on the estimation results we conclude that six of the parameter estimates are significantly different from 0 while $\delta_{F}$ is not. These results indicate strong uncertainty aversion in chartists but not fundamentalists since the parameter $\delta_{C}$ is significantly different from zero and hence the null hypothesis is rejected. Uncertainty aversion therefore appears to be an important feature of at least some traders in the foreign exchange market. One intuitive interpretation for this result could be as follows; fundamentalists have a strong belief in one economic model and their expectations are tied down by the exogenous interest rates through $\bar{s}$ but chartists use an 'ad hoc' time series model driven by past realised rates and hence are naturally more uncertain as to the true model driving the fundamental exchange rate. The average of uncertainty averse agents in the market is $21.56 \%$ which indicates a significant impact on the realised exchange rate.

$$
\text { [Insert Figure 1 here] }
$$

In order to test the joint hypothesis of no uncertainty aversion in all traders we specify the null hypothesis that all traders in the market are uncertainty neutral (simply quadratic utility maximisers) by:

$$
H_{0}: \delta_{F}=\delta_{C}=0
$$


with the alternative

$$
H_{1}: \delta_{F}>0 \text { or } / \text { and } \delta_{C}>0
$$

We test this hypothesis using Wald test on the restriction $\delta_{F}=\delta_{C}=0$. The corresponding $\mathrm{F}$ statistic is computed by

$$
F=\frac{\left(R S S_{\delta_{C}=\delta_{F}=0}\left(\hat{\theta}_{3: 7}\right)-R S S_{U}(\hat{\theta})\right) /(7-2)}{\hat{\sigma}^{2}} \sim F_{7-2, n-7},
$$

where $R S S_{\delta_{C}=\delta_{F}=0}\left(\hat{\theta}_{3: 7}\right)$ and $R S S_{U}(\hat{\theta})$ are residual sum of squares of the restricted and unrestricted models and $\hat{\sigma}^{2}$ is the estimate of the variance of the residuals from the unrestricted model. Estimates of the parameters of the restricted model is given in Table 2. The value of the test statistic is $F=31.08$ which is substantially larger than $1 \%$ critical value $F_{0.01,1, \infty}=6.895$. Thus, we reject the null hypothesis of no uncertainty aversion within traders in the FX market.

\subsection{Model Evaluation}

In order for us to have confidence in the test results reported above we need to be sure that the model is a reasonably good representation of reality (although we have used robust standard errors in the inference). We proceed to evaluate the model using three different approaches; first we compute standard residual diagnostic tests, then we compare the model with the random walk model in an out-of-sample prediction exercise and then finally we carry out two further prediction based tests to examine if there is any exploitable structure in the model's output - the PesaranTimmermann test for the directional change predictability and the Anatolyev-Gerko test for economic value based on using the forecasts from the model in a simple trading rule.

Before discussing these results we would like to stress that it is logically impossible to formally validate this model using just aggregate exchange rate data $4^{4}$ The model we have built has a complex "micro" structure which leads to an aggregate or macro output in the level of observed exchange rate. The question of model validation rests on whether we can uniquely identify the underlying "micro" model or whether in fact there may be a number of micro models that have the same implications for the observed aggregate exchange rate. The issue is one of

\footnotetext{
${ }^{4}$ We would like to thank a referee for emphasising this point to us.
} 
model identification as opposed to structure identification as originally discussed by Preston (2002) and more recently by Hendry, Lu and Mizon (2002). Standard parametric identification ensures there is a unique parametrisation of a structure and we are confident in that since we have a non singular parameter variance covariance matrix. However, parameter identification conditions do not rule out that there may be several different models which have the same observable implication. This is the issue we face in trying to validate our model and in fact it affects much econometric research although it is generally unacknowledged.

So while we use prediction tests below we note that a model without predictive ability could be correct - if the correct model is a random walk and secondly, in this particular case we cannot claim that predictive ability in the aggregate exchange rate necessarily implies that our heterogeneous agent model is the unique correctly specified data generation process. We interpret the following test results therefore as simply providing some indication that our model is not inconsistent with the data

We first examine the standard residual specification tests. Standard goodness of fit measures indicate an $R^{2}$ value of 0.98 . The residuals from the regression do not show significant evidence of autocorrelation (the p-value of Breusch-Godfrey Serial Correlation LM Test is 0.1319). Homoscedasticity is also rejected by Breush-Pagan's and White's tests (p-values are 0.0881 and 0.0011) and the augmented Dickey-Fuller tests for unit root rejects the non-stationarity of residuals ( $\mathrm{p}$-value is $<0.0001$ ). So we have some confidence the model structure is capturing much of the structure seen in the level of the exchange rate.

We now compare the ability of our model to predict out-of-sample compared to a random walk, following the classic paper by Meese and Rogoff (1983). We provide several tests on the predictive power of the model in a recursive one step ahead prediction mode in order to gain some form of model evaluation.

First, the root mean-square error of our model's out-of-sample forecasts is 0.003147 while that for the random walk model is 0.005093 . The resulting Diebold-Mariano statistic is -21.58 ( $\mathrm{p}$-value $<0.0001$ ) indicating clearly superior performance from our model compared to a random walk.

We next test the ability of the model to make correct one step-ahead predictions of the directional change of the exchange rate compared to random selection as well as a test of the significance of the economic value of these predictions in a simple trading rule. We use the Pesaran-Timmerman test (see Pesaran and Timmermann 
(1992), Pesaran and Timmermann (1994)) to examine directional change and the Anatolyev-Gerko test (see Anatolyev and Gerko (2005)) for assessing the economic significance of the predicted returns. The Pesaran-Timmermann statistic is used to test the null of no market timing or that the proportion of correct sign predictions equals the proportion which can be expected under the null of independence. The Anatolyev and Gerko test of no mean predictability, i.e. independence of the past exchange rate returns, is based on both market timing and a trading rule. Essentially this is a Hausman test that compares two estimates of mean returns from a simple trading rule, both of which will be consistent under the null of no predictability but will differ under the alternative (of dependence on past returns). The formal testing procedures are described in the Appendix.

The null hypothesis underlying both Pesaran-Timmermann and the AnatolyevGerko tests is essentially that the predictor from the model again cannot beat a random walk strategy. Rejection means that the model can predict significantly better than the baseline random walk model and hence we would expect it to dominate virtually all the standard macro based models of the exchange rate that were considered by Meese and Rogoff.

Following Kozhan and Salmon (2007), we consider different trading strategies which take into account the presence of uncertainty. We examine predictability of the exchange rate by measuring when the predicted value of the exchange rate deviates from the previous value by more than a given value $k$. The trading strategy based on the forecast is then to trade only if the forecast value for the next day's exchange rate is larger than the current price level by more than $k$ and not to trade otherwise. The rationale behind this is reflected in a so-called no-trade condition (see Dow and Werlang (1992)). If a forecast value does not differ from the current level of the exchange rate by more than $k$, then the trader does not believe that there is a clear enough signal on which to trade, in other words there is too much uncertainty in the market.

\section{[Insert Table 3 here]}

Table 3 shows the results of the above tests for different values of $k$. We see that with a small value of $k$ (0 and 0.0001) the Pesaran-Timmerman test does not reject the null of no-predictability. The Antolyev-Gerko test is unable to reject the null hypothesis for $k=0, \ldots, 0.0003$. However, as $k$ increases we see that the model has 
predictive power for both directional change and economic value. This just supports our contention that small predictive signals are noisy because of uncertainty in the market while large signals are informative and have predictive power. This indication of predictability, taking account of the $k$ uncertainty band, provides further empirical validation of the model over the random walk. Once again this suggest the model is better supported by the data than the standard macro fundamental models considered by Messe and Rogoff and is also consistent with the finding of uncertainty aversion in the market.

\section{Discussion and Interpretation}

The most important result is that we seem to have found is that at least some traders in the FX market appear to be uncertainty averse. The estimation results show that the inclusion of uncertainty averse agents improves the performance of the model (through the F test) and the uncertainty aversion parameter for chartists is significantly different from zero. However traders do not remain equally uncertainty averse throughout the sample. As we can see in Figure 2 there are periods of higher and lower uncertainty aversion in the market, but since fundamentalists are uncertainty neutral (as $\delta_{F}$ is insignificantly different from zero) these periods are highly correlated with the periods of chartist activity.

$$
\text { [Insert Figure 2 here] }
$$

Figure 2 plots the fraction of the different types of agent in the market. The majority of the time fundamentalists dominate chartists - the average fraction of fundamentalists over the whole period is $62.4 \%$. This means that exchange rate forecasts based on the macro indicators (fundamentals) are more precise and more profitable than the trend following approximation we have considered the chartists use. Moreover, the precision of these forecasts is quite tight which allows fundamentalists to be uncertainty neutral and more confident about their predictions. At the same time, it is chartists who are found to be mainly uncertainty averse.

Let us look at behaviour of traders closer and focus the analysis on two subperiods. If the fundamental price does not show clear trends, chartist expectation becomes less precise which leads to the increase of a number of uncertainty averse 
chartists in the market. As demands of uncertainty averse traders is smaller than demands of uncertainty neutral traders, chartists trade less actively during this period of time. However, during unexpected changes in the fundamental rate, fundamentalists make errors in their predictions and lose money. Evolutionary pressure will then cause fundamentalists to switch towards using chartists strategies, which increases the proportion of chartists in the market. In addition, in trying to push the price back to its fundamental value fundamentalists create short-term trends in the exchange rate. Chartists pick up on this trend, make money on it and their weight in the market expands. Once the exchange rate approaches the fundamental level and uncertainty in the market vanishes, the fundamentalists' forecast becomes more precise once again and the fraction of chartists immediately drops. This behaviour can be clearly observed in Figure 3. Spikes in fundamentalist activity mainly correspond to reversals in exchange rate trends when the chartist strategy becomes unprofitable. At that time chartists are mainly uncertainty averse and that helps them to survive in the market. As uncertainty averse traders consider the worst-case scenario, their demands are relatively small and they do not suffer from big losses. As long as trends become clearer and stronger the fraction of chartists increases. As uncertainty about the behaviour of the exchange rate in the short-term decreases, more and more chartists switch to an uncertainty neutral strategy. If changes in the exchange rate happen unexpectedly but in the same direction with the existing trend, as in October 2007, we observe a double effect - chartists benefit from the trend becomes stronger and fundamentalists lose because of the gap between their beliefs about the fundamental price and the exchange rate level. As the consequence of these events, we see a large switch towards the chartist strategy and a temporary decrease in fundamentalists' activity.

\section{[Insert Figure 3 here]}

The second example (see Figure 44) shows the coexistence of fundamentalists and chartists in the market. The relative fractions of agent types do not change much if there are trends in the fundamental price (from the middle of June 1999 to the middle of August 1999). Both fundamentalist and chartist strategies are profitable as they can simultaneously exploit trends in the exchange rate and the movement of the exchange rate towards the fundamental price. This leads to approximately equal revenues for both chartists and fundamentalists: the former predict a trend and the 
latter follow the fundamental price. During this trend period in the fundamental price we observe the persistent presence of chartists in the market. The difference in wealth during this period is less volatile than usual which brings some stability to the proportion of traders in the market. In this case there is a reversal in the trend at the beginning of July 2006, chartists quickly pick up on the downtrend and hence do not disappear from the market.

\section{[Insert Figure 4 here]}

We can also observe in Figure 4 that even in the absence of clear trends in the exchange rate at the end of November 1999, a large difference between the fundamental rate and the realised exchange rate immediately causes a big drop in the proportion of fundamentalists in the market.

The important observation is that the majority of chartists have been found to be uncertainty averse while the degree of uncertainty aversion among fundamentalists is almost zero. Periods when chartists are more confident in the market (the degree of uncertainty is low) are usually at the end of active chartist periods. The intuition behind this behaviour is that once technical traders become more powerful (their proportion increases) they create trends effectively by their own herding behaviour. At the same time, as this trend becomes clear chartists become more confident in their predictions. Hence they use point predictors to make money rather than interval-based forecasts which would reflect uncertainty.

The proportion of uncertainty averse chartists is relatively stable over the whole period of time. This is explained by the fact that uncertainty averse traders are prepared for the worst possible outcome and are less sensitive to large negative shocks in the exchange rate. The proportion of uncertainty neutral traders varies over time and depends highly on market conditions.

From the estimation results we see that the parameter $\delta_{F}$ which reflects uncertainty aversion of fundamentalist traders is almost zero so we are not able to distinguish the performance of uncertainty neutral fundamentalists from the performance of uncertainty averse fundamentalists, they are essentially the same. So in fact their proportions in the market are identical and for this reason we present all fundamentalists as being uncertainty neutral. If fundamentalists predict the future rate incorrectly and face losses it does not make any difference to them to switch to an uncertainty averse strategy as it will not improve their performance. 


\section{Conclusions}

In this paper we provide what we believe to be the first formal test of uncertainty aversion within traders in an FX market using observed daily GBP/USD data over a ten year period 2.01.1997 to 30.06.2008. We have developed a model of exchange rate formation with uncertainty averse investors that can either hold fundamental or chartist beliefs which has been estimated using nonlinear least squares and Unscented Kalman Filter techniques. The estimation results indicate the statistical significance of uncertainty aversion within the market and in particular we find that fundamentalists are largely uncertainty neutral while chartists are uncertainty averse. We have also shown through a range of statistical tests that the model is not inconsistent with observed data and dominates the random walk model for exchange rates. The activity of chartists increases during periods showing clear trends in the level of the exchange rate and they become more confident (uncertainty neutral) when these trends are long. As soon as any trend breaks down the majority of traders switch back to the fundamentalist strategy.

The approach proposed in the paper has several limitations. Chartists are usually more sophisticated that simply trend followers and therefore their forecasts might be more precise than suggested by the model. This is especially true due to the dramatic increase of algorithmic trading among investors and the use of such techniques as genetic programming. Also, our model has been estimated using daily data while in real markets prices are obviously determined on an tick by tick basis.

Despite these limitations the paper provides a first step to detecting and testing the behavioural attitude of FX traders to uncertainty by providing what may be the first empirical test of. It therefore extends the existing literature of decision making under uncertainty and provides an approach to rigorously examining further models on real data.

We have not discussed the implications of the model for the carry trade but it is clear from the structure of the model that the UIP condition will be violated by the realised market clearing exchange rates for considerable periods of due to the presence of uncertainty averse heterogeneous agents in the market. 


\section{References}

Anatolyev, S. and Gerko, A.: 2005, A trading approach to testing for predictability, Journal of Business 85 Economic Statistics 23(4), 455-462.

Andersen, E., Hansen, L. and Sargent, T.: 2000, Robustness direction and the price of risk, Working Paper, University of Chicago .

Bewley, T.: 2002, Knightian decision theory. part I, Decisions in Economics and Finance 25, 79-100.

Blume, L., Easley, D. and OHara, M.: 1994, Market statistics and technical analysis: the role of volume, Journal of Finance 49, 153181.

Boswijk, H., Hommes, C. and Manzan, S.: 2007, Behavioral heterogeneity in stock prices, Journal of Economic Dynamics and Control 31(6), 1938-1970.

Brock, W. and Hommes, C.: 1998, Heterogeneous beliefs and routes to chaos in a simple asset pricing model, Journal of Economic Dynamics and Control 22, $1235-1274$.

Chen, Z. and Epstein, L.: 2002, Ambiquity, risk and asset returns in continuous time, Econometrica 70, 1403-1443.

Cheung, Y., Chinn, M. and Marsh, I.: 2004, How do uk-based foreign exchange dealers think their market operates?, International Journal of Finance and Economics 9(4), 289-306.

De Grauwe, P. and Grimaldi, M.: 2006, The Exchange Rate in a Behavioral Finance Framework, Princeton University Press.

Della Corte, P., Sarno, L. and Tsiakas, I.: 2008, An economic evaluation of empirical exchange rate models, Review of Financial Studies forthcoming.

Dow, J. and Werlang, S.: 1992, Uncertainty aversion, risk aversion, and the optimal choice of portfolio, Econometrica 60(1), 197-204.

Ellsberg, D.: 1961, Risk, ambiguity and Savage axioms, Quarterly Journal of Economics 75, 643-669. 
Epstein, L. and Wang, T.: 1994, Intertemporal asset pricing under Knightian uncertainty, Econometrica 62(2), 283-322.

Garlappi, L., Uppal, R. and Wang, T.: 2004, Portfolio selection with parameter and model uncertainty: A multi-prior approach, Working Paper .

Gilboa, I. and Schmeidler, D.: 1989, Maxmin expected utility with non-unique prior, Journal of Mathematical Economics 18, 141-153.

Hansen, L. and Sargent, T.: 2007, Robustness, Princeton University Press.

Hellwig, M.: 1982, Rational expectations equilibrium with conditioning on past prices: a mean-variance example, Journal of Economic Theory 26, 279-312.

Hendry, D., Lu, M. and Mizon, G.: 2002, Model identification and non-unique structure, Nuffield Economics Research via WWW 2002-W10.

Julier, S. and Uhlmann, J.: 2004, Unscented filtering and nonlinear transformation, IEEE Review $\mathbf{9 2 ( 3 ) .}$

Keynes, J.: 1921, A Treatise on Probability, McMillan, London.

Kirman, A.: 1993, Ants, rationality and recruitment, Quarterly Journal of Economics 108, 137-156.

Kirman, A., Ricciotti, R. F. and Topol, R. L.: 2006, Bubbles in foreign exchange markets: It takes two to tango, Working Paper.

Knight, F.: 1921, Risk, Uncertainty and Profit, Boston: Houghton Mifflin.

Kozhan, R. and Salmon, M.: 2007, On uncertainty, market timing and the predictability of tick by tick exchange rates, FERC Working Paper.

Maccheroni, F., Marinacci, M. and Rustichini, A.: 2006, Ambiguity aversion, robustness, and the variational representation of preferences, Econometrica $74(6), 1447-1498$.

Maccheroni, F., Marinacci, M., Rustichini, A. and Taboga, M.: 2008, Portfolio selection with monotone mean-variance preferences, Temi di discussione (Economic working papers) 664. 
Maenhout, P.: 2004, Robust portfolio rule and asset pricing, The Review of Financial Studies 17(4), 951-983.

Mangelsdorf, L. and Weber, M.: 1994, Testing Choquet expected utility, Journal of Economic Behavior and Organization 25, 437-457.

Meese, R. and Rogoff, K.: 1983, Empirical exchange rate models of the seventies: Do they fit out of sample?, Journal of International Economics 14, 3-24.

Menkhoff, L. and Taylor, M.: 2007, The obstinate passion of foreign exchange professionals: Technical analysis, Journal of Economic Literature 45(4), 936-972.

Pesaran, H. and Timmermann, A.: 1992, A simple nonparametric test of predictive performance, Journal of Business \& Economic Statistics 10(4), 461-465.

Pesaran, H. and Timmermann, A.: 1994, A generalization of the non-parametric Henriksson-Merton test of market timing, Economic Letters 44, 1-7.

Preston, A.: 2002, Concepts of Structure and Model Identifiability for Econometric Systems, Stability and Inflation, Wiley.

Quiggin, J.: 1982, A theory of anticipated utility, Journal of Economic Behavior and Organization 3, 323-343.

Schmeidler, D.: 1989, Subjective probability and expected utility without additivity, Econometrica 57, 571-587.

Taylor, M. and Allen, H.: 1992, The use of technical analysis in the foreign exchange market, Journal of International Money and Finance 11(3), 304-314.

Uppal, R. and Wang, T.: 2003, Model misspecification and underdiversification, Journal of Finance 58, 2465-2486.

Van der Merwe, R.: 1998, Sigma-Point Kalman Filters for Probabilistic Inference in Dynamic State-Space Models, PhD thesis, University of Stellenbosch.

Wakker, P.: 2001, Testing and characterizing properties of nonadditive measures through violations of the sure-thing principle, Econometrica 69(4), 1039-1059.

White, H. and Domowitz, I.: 1984, Nonlinear regression with dependant observations, Econometrica 52(1), 143-161. 
Zhao, Y., Haussmann, U. and Ziemba, W.: 2003, A dynamic investment model with control on the portfolio's worst case outcome, Mathematical Finance 13(4), 481-501. 


\section{List of Figures}

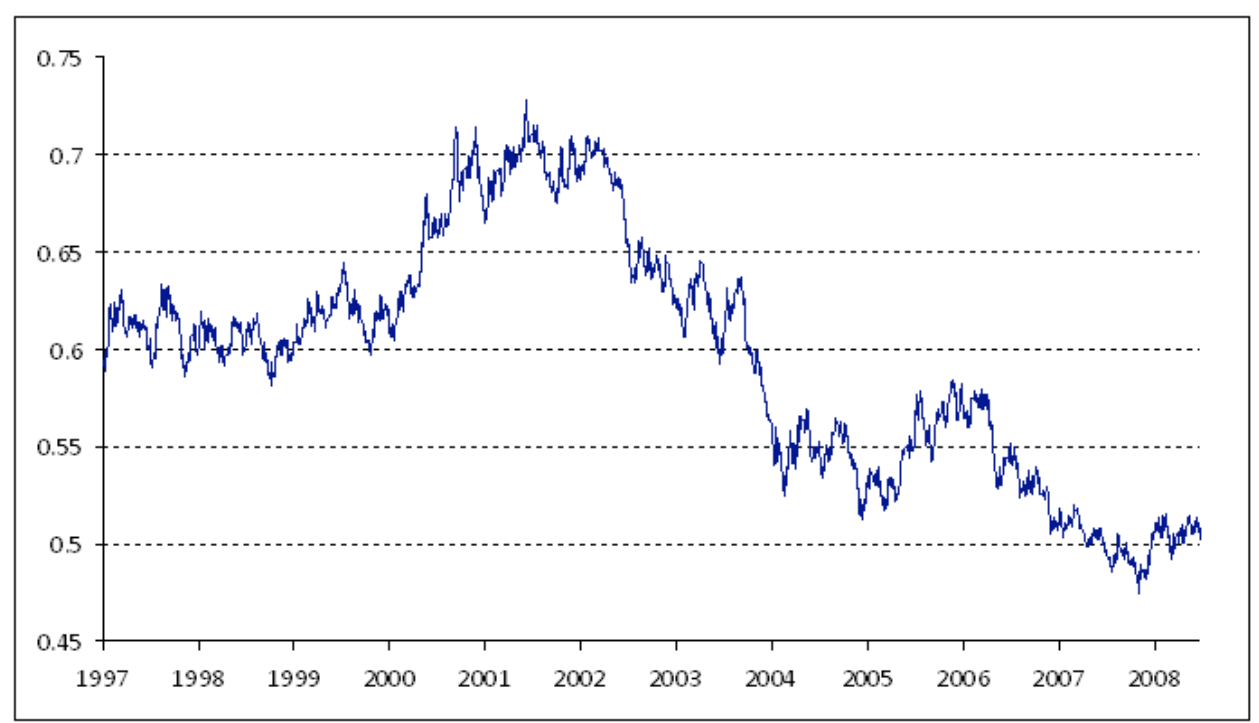

Figure 1: Daily GBP/USD prices during 2 January 1997 - 30 June 2008 (top) and the estimated model residuals (bottom).

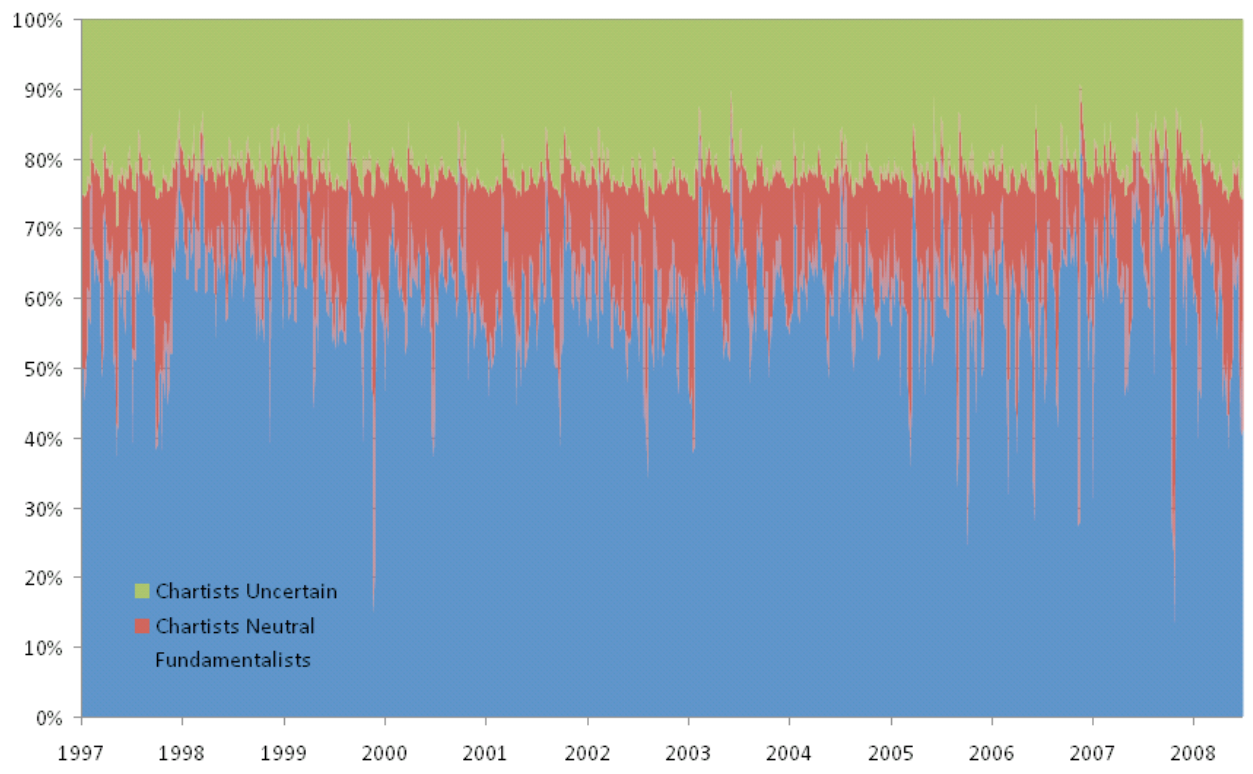

Figure 2: Proportions of traders in the market - fundamentalists, chartists uncertainty averse and chartists uncertainty neutral. 

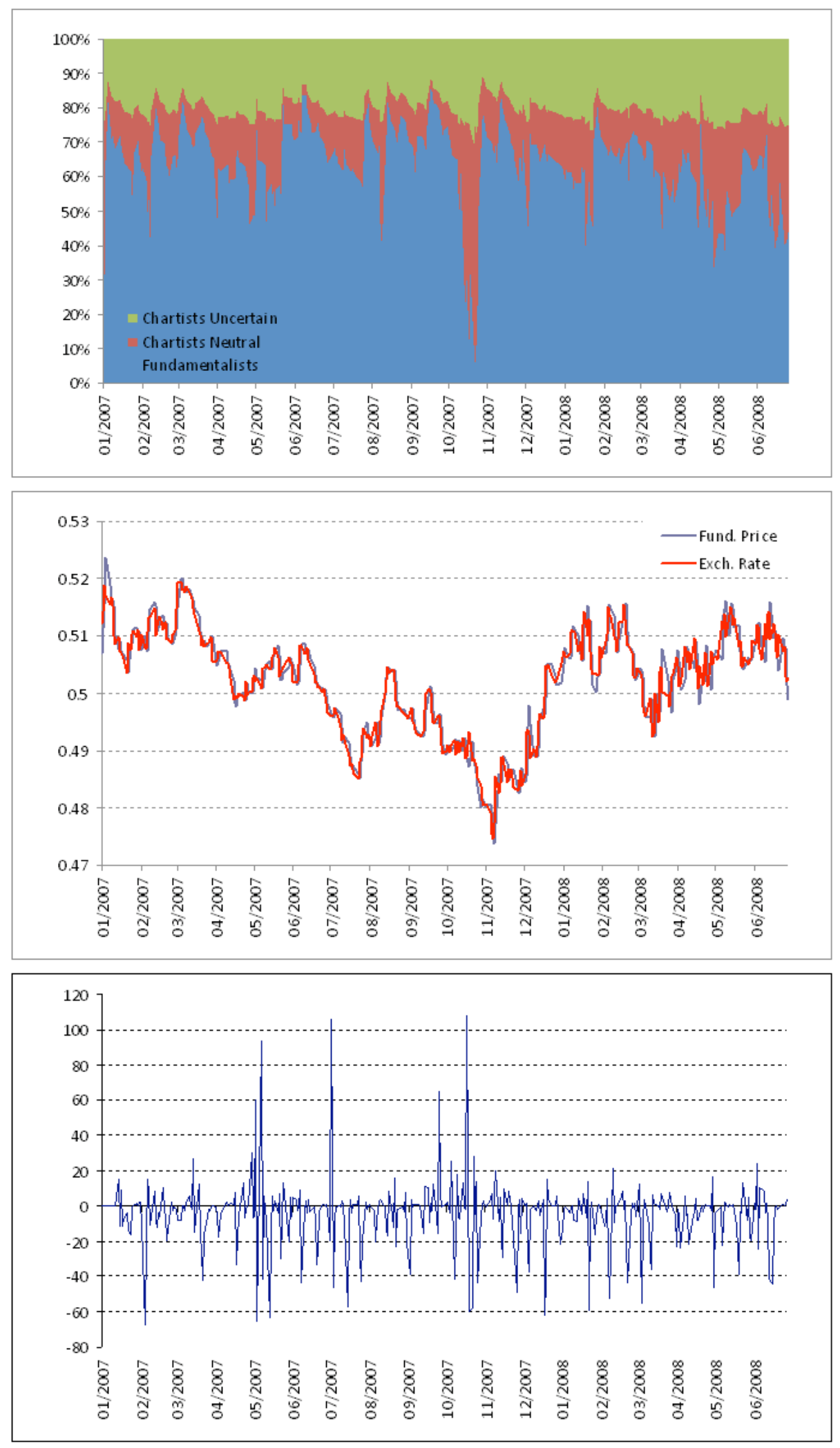

Figure 3: Proportion of trader types, exchange rate levels vs. fundamental price, interest rate differential and difference in utilities between fundamentalist and chartist traders over period from 2 January 2007 to 30 June 2008. 

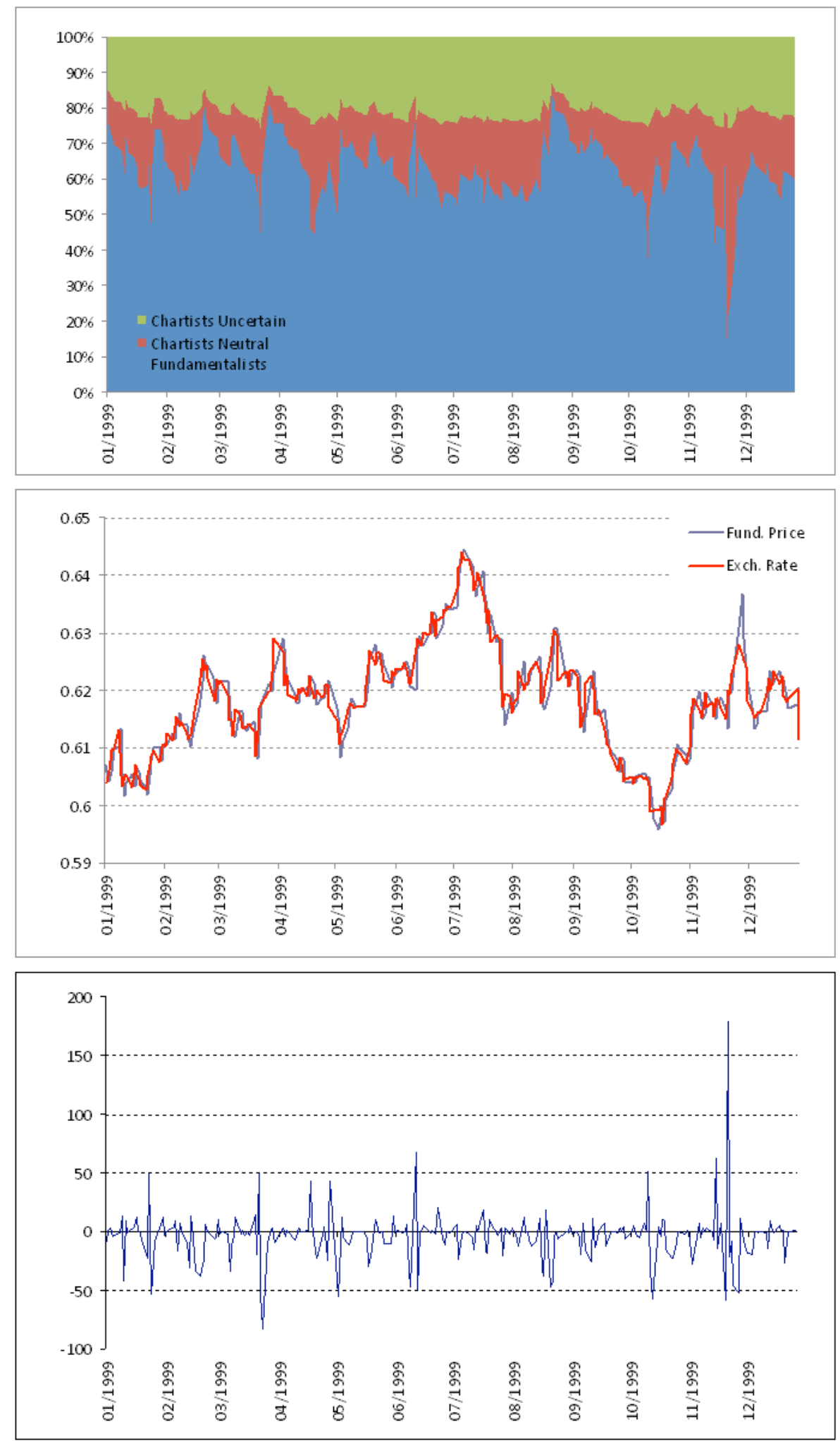

Figure 4: Proportions of trader types, exchange rate levels vs. fundamental price and difference in utilities between fundamentalist and chartist agents over 1997. 
Table 1: Parameters Estimates: Unrestricted Model

\begin{tabular}{c|c|c|c}
\hline \hline Parameters & Estimates & Std. deviation & p-value \\
\hline \hline$\delta_{F}$ & $1.35677 \cdot 10^{-9}$ & $3.98765 \cdot 10^{-3}$ & $>0.5000$ \\
$\delta_{C}$ & 0.01652 & $1.56621 \cdot 10^{-3}$ & $<0.0001$ \\
$\sigma_{\bar{s}}$ & 0.00527 & $2.12940 \cdot 10^{-4}$ & $<0.0001$ \\
$v$ & 0.99868 & $8.98731 \cdot 10^{-2}$ & $<0.0001$ \\
$h$ & 0.07832 & $1.33536 \cdot 10^{-2}$ & $<0.0001$ \\
$\sigma$ & 0.00120 & $2.45013 \cdot 10^{-4}$ & $<0.0001$ \\
$\beta$ & 0.01374 & $5.59801 \cdot 10^{-3}$ & $<0.0001$ \\
\hline \hline
\end{tabular}

Parameters estimates of the model based on the nonlinear least squares estimation method (column 2). Columns 3 and 4 contain standard deviations of estimates and their p-values of the test for significance.

Table 2: Parameters Estimates: Restricted Model

\begin{tabular}{c|c|c|c}
\hline \hline Parameters & Estimates & Std. deviation & p-value \\
\hline \hline$\sigma_{\bar{s}}$ & 0.01311 & $4.78994 \cdot 10^{-4}$ & $<0.0001$ \\
$v$ & 0.99982 & $1.59371 \cdot 10^{-2}$ & $<0.0001$ \\
$h$ & 0.11988 & $6.33276 \cdot 10^{-3}$ & $<0.0001$ \\
$\sigma$ & 0.00443 & $1.65087 \cdot 10^{-4}$ & $<0.0001$ \\
$\beta$ & 0.03721 & $1.35288 \cdot 10^{-3}$ & $<0.0001$ \\
\hline \hline
\end{tabular}

Parameters estimates of the model based on the nonlinear least squares estimation method (column 2) under the assumption $\delta_{F}=0$ and $\delta_{C}=0$. Columns 3 and 4 contain standard deviations of estimates and their p-values of the test for significance. 
Table 3: Tests for model's predictive power

\begin{tabular}{c|c|c|c|c|c|c}
\hline \hline $\mathbf{k}$ & $\begin{array}{c}\text { Directional } \\
\text { changes, } \%\end{array}$ & $\begin{array}{c}\text { Average of } \\
\text { daily returns }\end{array}$ & P-T stat. & P-T p-value & A-G stat. & A-G p-value \\
\hline \hline 0 & 51.00 & 0.019124 & 0.4505 & 1.661612 & 2.07505 & 0.2658 \\
\hline 0.0001 & 51.42 & 0.0223366 & 1.34829 & 2.42258 & 0.8186 & 0.2065 \\
\hline 0.0002 & 52.03 & 0.0315083 & 1.53098 & 3.40596 & 1.2377 & 0.1079 \\
\hline 0.0003 & 52.36 & 0.0520307 & 1.35631 & 5.36543 & 1.1715 & 0.1207 \\
\hline 0.0004 & 54.06 & 0.0722422 & 1.95846 & 7.39451 & 1.2492 & 846 \\
\hline 0.0005 & 54.20 & 0.0693297 & 1.7131 & 7.46285 & 1.6672 & 0.1058 \\
\hline 0.0006 & 53.45 & 0.0680766 & 1.14425 & 7.27567 & 1.9651 & 566 \\
\hline 0.0007 & 52.15 & 0.0780691 & 0.621641 & 7.27567 & 8.31451 & 0.0477 \\
\hline \hline
\end{tabular}

The trading strategy based on the forecast is to trade only if the forecast value for the next day's exchange rate is larger than the current price level more than $k$ and not to trade otherwise. Percentages of correct directional changes predictions and average daily returns based on the strategy are given in columns 2 and 3 for corresponding values of $k$. Columns 4 and 5 present values of statistic and the corresponding p-values for the Pesaran-Timmermann test, columns 6 and 7 provide results of Anatolyev-Gerko test. Column 8 shows numbers of transactions during the horizon. 


\section{Appendix}

Proof of Lemma 1.1. This lemma is an easy consequence of Lemma 1.2 letting $\delta_{I}=0$.

Proof of Lemma 1.2. Given $\tilde{s}$ one can rewrite the expected utility of the terminal wealth as

$$
I(\tilde{s})=\left(1+r_{t}\right)\left(W_{t}-s_{t} f_{t}^{u}\right)+\tilde{s}\left(1+\rho_{t}\right) f_{t}^{u}-\gamma\left(1+\rho_{t}\right)^{2} f_{t}^{u} \sigma^{2}
$$

where $\sigma^{2}=V\left(s_{t+1}\right)$.

The explicit form of the preference functional

$$
V\left(W_{t+1}\left(f_{t}^{u}\right)\right)=\min _{\tilde{s} \in\left[E_{t}\left(s_{t+1} \mid I\right)-\delta_{I}, E_{t}\left(s_{t+1} \mid I\right)+\delta_{I}\right]} I(\tilde{s})
$$

can be found through the minimisation problem $I(\tilde{s})_{\tilde{s} \in\left[E_{t}\left(s_{t+1} \mid I\right)-\vec{\delta}_{I}, E_{t}\left(s_{t+1} \mid I\right)+\delta_{I}\right]}$ min. The derivative of the functional $I(\tilde{s})$ is

$$
\frac{\partial I(\tilde{s})}{\partial \tilde{s}}=\left(1+\rho_{t}\right) f_{t}^{u}
$$

hence, $\frac{\partial I(\tilde{s})}{\partial \tilde{s}} \geq 0$ if $f_{t}^{u} \geq 0$ and $\frac{\partial I(\tilde{s})}{\partial \tilde{s}}<0$ if $f_{t}^{u}<0$. Let us denote

$$
\tilde{s}\left(f_{t}^{u}\right)=\left\{\begin{array}{ll}
E_{t}\left(s_{t+1} \mid I\right)-\delta_{I} & \text { if } \quad f_{t}^{u} \geq 0 \\
E_{t}\left(s_{t+1} \mid I\right)+\delta_{I} & \text { if } \quad f_{t}^{u}<0
\end{array}=\underset{\tilde{s} \in\left[E_{t}\left(s_{t+1} \mid I\right)-\delta_{I}, E_{t}\left(s_{t+1} \mid I\right)+\delta_{I}\right]}{\operatorname{argmin}} I(\tilde{s}) .\right.
$$

The expected utility can be rewritten as

$$
V\left(f_{t}^{u}\right)=\left(1+r_{t}\right)\left(W_{t}-s_{t} f_{t}^{u}\right)+\tilde{s}\left(f_{t}^{u}\right)\left(1+\rho_{t}\right) f_{t}^{n}-\gamma\left(1+\rho_{t}\right)^{2} f_{t}^{u 2} \sigma^{2}
$$

At the point $f_{t}^{u}=0$ the preference functional $V\left(f_{t}^{u}\right)=\left(1+r_{t}\right) W_{t}$ does not depend on $\tilde{s}\left(f_{t}^{u}\right)$ and therefore is continuous function on $\mathbb{R}$.

The derivative of the preference functional is given by the expression

$$
\frac{\partial V}{\partial f_{t}^{u}}= \begin{cases}2 \gamma \sigma^{2}\left(1+\rho_{t}\right)^{2}\left(C_{\min }(I)-f_{t}^{u}\right), & f_{t}^{n}>0 \\ 2 \gamma \sigma^{2}\left(1+\rho_{t}\right)^{2}\left(C_{\max }(I)-f_{t}^{u}\right), & f_{t}^{u}<0,\end{cases}
$$

where

$$
\begin{aligned}
& C_{\min }(I)=\frac{\left(E_{t}\left(s_{t+1} \mid I\right)-\delta_{I}\right)\left(1+\rho_{t}\right)-s_{t}\left(1+r_{t}\right)}{2 \gamma E_{t}\left(s_{t+1}^{2} \mid I\right)\left(1+\rho_{t}\right)^{2}}, \\
& C_{\max }(I)=\frac{\left(E_{t}\left(s_{t+1} \mid I\right)+\delta_{I}\right)\left(1+\rho_{t}\right)-s_{t}\left(1+r_{t}\right)}{2 \gamma E_{t}\left(s_{t+1}^{2} \mid I\right)\left(1+\rho_{t}\right)^{2}} .
\end{aligned}
$$


Thus,

$$
f_{t}^{u}=\left\{\begin{array}{lll}
C_{\min }(I) & \text { if } & C_{\min }(I)>0, \\
C_{\max }(I) & \text { if } & C_{\max }(I)<0, \\
0 & \text { if } & C_{\min }(I) \leq 0 \leq C_{\max }(I) .
\end{array}\right.
$$

The statement of the lemma can be easily obtained from the previous equation.

Pesaran-Timmermann Test. Let $s_{t}$ be the realised value of the exchange rate and $s_{t \mid t-1}-$ its forecast. Define the probabilities

$$
\begin{array}{ll}
P_{11}=P\left(s_{t \mid t-1}<0, s_{t}<0\right), & P_{12}=P\left(s_{t \mid t-1}<0, s_{t} \geq 0\right), \\
P_{21}=P\left(s_{t \mid t-1} \geq 0, s_{t}<0\right), & P_{22}=P\left(s_{t \mid t-1} \geq 0, s_{t} \geq 0\right) .
\end{array}
$$

The diagonal elements of this contingency table provide the proportion of correct predictions. $P_{i j}$ denotes the probability of a realisation in the cell of the $i^{\prime} t h$ row and $j^{\prime}$ th column of the contingency table. In general, the Pesaran-Timmermann test considers a number of categories $i, j \in\{1, \ldots, m\}$; we only need to consider $m=2$. Denote by $P_{i 0}=\sum_{j=1}^{m} P_{i j}$ the probability of cells in the $i^{\prime}$ th row and $P_{0 j}=\sum_{i=1}^{m} P_{i j}$ the probability of cells in the $j^{\prime} t h$ column. The null hypothesis is expressed as

$$
H 0: \sum_{i=1}^{m}\left(\hat{P}_{i i}-\hat{P}_{i 0} \hat{P}_{0 i}\right)=0,
$$

which says that the predictor cannot predict significantly more correct directional changes that a random walk predictor (i.e. 50\%). Here the probabilities estimates $\hat{P}_{i j}$ are frequencies of the corresponding events observed in the data.

The test is based on the standardised statistic

$$
z_{n}=\sqrt{n} V_{n}^{-\frac{1}{2}} Z_{n} \stackrel{a}{\sim} N(0,1)
$$

where $n$ is the number of observations, and

$$
\begin{aligned}
Z_{n} & =\sum_{i=1}^{m}\left(\hat{P}_{i i}-\hat{P_{i 0}} \hat{P}_{0 i}\right) \\
V_{n} & =\left(\frac{\partial f(\mathbf{P})}{\partial \mathbf{P}}\right)_{\mathbf{P}=\hat{\mathbf{P}}}^{\prime}\left(\hat{\Psi}-\hat{\mathbf{P}} \hat{\mathbf{P}}^{\prime}\right)\left(\frac{\partial f(\mathbf{P})}{\partial \mathbf{P}}\right)_{\mathbf{P}=\hat{\mathbf{P}}}
\end{aligned}
$$

$\hat{\Psi}$ is an $m^{2} \times m^{2}$ diagonal matrix with $\hat{\mathbf{P}}$ as its diagonal elements,

$$
\left(\frac{\partial f(\mathbf{P})}{\partial \mathbf{P}}\right)_{\mathbf{P}=\hat{\mathbf{P}}}=\left\{\begin{array}{cc}
1-P_{0 i}-P_{i 0} & \text { for } i=j \\
-P_{j 0}-P_{0 i} & \text { for } i \neq j
\end{array}\right.
$$


Anatolyev-Gerko Test. Let $r_{t}$ be the observed log-returns of the exchange rate and $r_{t \mid t-1}$ be their forecasts for $t=1, \ldots, n$. The forecasts depend on the past information $\mathcal{F}_{t-1}=\left\{r_{t-1}, r_{t-2}, \ldots\right\}$. Let the trading rule of the investor be based on the forecast variable $r_{t \mid t-1}$, in particular, the investor takes a long position in USD if $r_{t \mid t-1} \geq 0$ and a short position in dollars if $r_{t \mid t-1}<0$. Then the one-period return from using the trading strategy is $R_{t}=\operatorname{sign}\left(r_{t \mid-1}\right) \cdot r_{t}$. The null hypothesis is conditional mean independence so that

$$
H_{0}: E\left(r_{t} \mid \mathcal{F}_{t-1}\right)=\mathrm{const}
$$

or that $r_{t \mid t-1}$ and $r_{t}$ are independent. The expected one-period return $E\left(R_{t}\right)$ can be consistently estimated under the null by two estimators:

$$
A_{n}=\frac{1}{n} \sum_{t} R_{t}
$$

and

$$
B_{n}=\left(\frac{1}{n} \sum_{t} \operatorname{sign}\left(r_{t \mid t-1}\right)\right)\left(\frac{1}{n} \sum_{t} r_{t}\right) .
$$

$A_{n}$ estimates the average return from using the trading strategy whereas $B_{n}$ estimates the average return from using the benchmark strategy that issues buy/sell signals randomly with probabilities corresponding to the proportion of buys and sells implied ex post by the trading strategy. When $r_{t}$ is predictable investing in the trading strategy will generate higher returns than the benchmark and the difference between $A_{n}$ and $B_{n}$ will be sizable. The variance of the difference $A_{n}-B_{n}$ is

$$
V=\operatorname{Var}\left(A_{n}-B_{n}\right)=\frac{4(n-1)}{n^{2}} p_{r}\left(1-p_{r}\right) \operatorname{Var}\left(r_{t}\right),
$$

where $p_{r}=\operatorname{Pr}\left\{\operatorname{sign}\left(r_{t \mid t-1}\right)=1\right\}$. The estimator for the variance is $\hat{V}=\frac{4}{n^{2}} \hat{p}_{r}(1-$ $\left.\hat{p}_{r}\right) \sum_{t}\left(r_{t}-r_{t \mid t-1}\right)^{2}$ with $\hat{p}_{r}=\frac{1}{2}\left(1+\frac{1}{n} \sum_{t} \operatorname{sign}\left(r_{t \mid t-1}\right)\right)$. The excess profitability statistic is then given by

$$
E P=\frac{A_{n}-B_{n}}{\sqrt{\hat{V}}} \stackrel{d}{\rightarrow} N(0,1)
$$

under the null hypothesis. 


\section{List of other working papers:}

\section{8}

1. Roman Kozhan and Rozalia Pal, Firms' Investment under Financial Constraints: A Euro Area Investigation, WP08-07

2. Roman Kozhan and Mark Salmon, On Uncertainty, Market Timing and the Predictability of Tick by Tick Exchange Rates, WP08-06

3. Roman Kozhan and Mark Salmon, Uncertainty Aversion in a Heterogeneous Agent Model of Foreign Exchange Rate Formation, WP08-05

4. Roman Kozhan, Non-Additive Anonymous Games, WP08-04

5. Thomas Lux, Stochastic Behavioral Asset Pricing Models and the Stylized Facts, WP08-03

6. Reiner Franke, A Short Note on the Problematic Concept of Excess Demand in Asset Pricing Models with Mean-Variance Optimization, WP08-02

7. Alexandra Dias, Semi-parametric estimation of joint large movements of risky assets, WP08-01

\section{7}

1. Timur Yusupov and Thomas Lux, The Efficient Market Hypothesis through the Eyes of an Artificial Technical Analyst: An Application of a New Chartist Methodology to High-Frequency Stock Market Data, WP07-13

2. Liu Ruipeng, Di Matteo and Thomas Lux, True and Apparent Scaling: The Proximity of the Markov- Switching Multifractal Model to Long-Range Dependence, WP07-12

3. Thomas Lux, Rational Forecasts or Social Opinion Dynamics? Identification of Interaction Effects in a Business Climate Survey, WP07-11

4. Thomas Lux, Collective Opinion Formation in a Business Climate Survey, WP07-10

5. Thomas Lux, Application of Statistical Physics in Finance and Economics, WP07-09

6. Reiner Franke, A Prototype Model of Speculative Dynamics With Position-Based Trading, WP07-08

7. Reiner Franke, Estimation of a Microfounded Herding Model On German Survey Expectations, WP07-07

8. Cees Diks and Pietro Dindo, Informational differences and learning in an asset market with boundedly rational agents, WP07-06

9. Markus Demary, Who Do Currency Transaction Taxes Harm More: Short-Term Speculators or Long-Term Investors?, WP07-05

10. Markus Demary, A Heterogenous Agents Model Usable for the Analysis of Currency Transaction Taxes, WP07-04

11. Mikhail Anufriev and Pietro Dindo, Equilibrium Return and Agents' Survival in a Multiperiod Asset Market: Analytic Support of a Simulation Model, WP07-03

12. Simone Alfarano and Michael Milakovic, Should Network Structure Matter in Agent-Based Finance?, WP07-02

13. Simone Alfarano and Reiner Franke, A Simple Asymmetric Herding Model to Distinguish Between Stock and Foreign Exchange Markets, WP07-01

\section{6}

1. Roman Kozhan, Multiple Priors and No-Transaction Region, WP06-24

2. Martin Ellison, Lucio Sarno and Jouko Vilmunen, Caution and Activism? Monetary Policy Strategies in an Open Economy, WP06-23

3. Matteo Marsili and Giacomo Raffaelli, Risk bubbles and market instability, WP06-22

4. Mark Salmon and Christoph Schleicher, Pricing Multivariate Currency Options with Copulas, WP06-21 
5. Thomas Lux and Taisei Kaizoji, Forecasting Volatility and Volume in the Tokyo Stock Market: Long Memory, Fractality and Regime Switching, WP06-20

6. Thomas Lux, The Markov-Switching Multifractal Model of Asset Returns: GMM Estimation and Linear Forecasting of Volatility, WP06-19

7. Peter Heemeijer, Cars Hommes, Joep Sonnemans and Jan Tuinstra, Price Stability and Volatility in Markets with Positive and Negative Expectations Feedback: An Experimental Investigation, WP06-18

8. Giacomo Raffaelli and Matteo Marsili, Dynamic instability in a phenomenological model of correlated assets, WP06-17

9. Ginestra Bianconi and Matteo Marsili, Effects of degree correlations on the loop structure of scale free networks, WP06-16

10. Pietro Dindo and Jan Tuinstra, A Behavioral Model for Participation Games with Negative Feedback, WP06-15

11. Ceek Diks and Florian Wagener, A weak bifucation theory for discrete time stochastic dynamical systems, WP06-14

12. Markus Demary, Transaction Taxes, Traders' Behavior and Exchange Rate Risks, WP06-13

13. Andrea De Martino and Matteo Marsili, Statistical mechanics of socio-economic systems with heterogeneous agents, WP06-12

14. William Brock, Cars Hommes and Florian Wagener, More hedging instruments may destabilize markets, WP06-11

15. Ginwestra Bianconi and Roberto Mulet, On the flexibility of complex systems, WP06-10

16. Ginwestra Bianconi and Matteo Marsili, Effect of degree correlations on the loop structure of scale-free networks, WP06-09

17. Ginwestra Bianconi, Tobias Galla and Matteo Marsili, Effects of Tobin Taxes in Minority Game Markets, WP06-08

18. Ginwestra Bianconi, Andrea De Martino, Felipe Ferreira and Matteo Marsili, Multi-asset minority games, WP06-07

19. Ba Chu, John Knight and Stephen Satchell, Optimal Investment and Asymmetric Risk for a Large Portfolio: A Large Deviations Approach, WP06-06

20. Ba Chu and Soosung Hwang, The Asymptotic Properties of AR(1) Process with the Occasionally Changing AR Coefficient, WP06-05

21. Ba Chu and Soosung Hwang, An Asymptotics of Stationary and Nonstationary AR(1) Processes with Multiple Structural Breaks in Mean, WP06-04

22. Ba Chu, Optimal Long Term Investment in a Jump Diffusion Setting: A Large Deviation Approach, WP06-03

23. Mikhail Anufriev and Gulio Bottazzi, Price and Wealth Dynamics in a Speculative Market with Generic Procedurally Rational Traders, WP06-02

24. Simonae Alfarano, Thomas Lux and Florian Wagner, Empirical Validation of Stochastic Models of Interacting Agents: A "Maximally Skewed" Noise Trader Model?, WP06-01

\section{5}

1. Shaun Bond and Soosung Hwang, Smoothing, Nonsynchronous Appraisal and CrossSectional Aggreagation in Real Estate Price Indices, WP05-17

2. Mark Salmon, Gordon Gemmill and Soosung Hwang, Performance Measurement with Loss Aversion, WP05-16

3. Philippe Curty and Matteo Marsili, Phase coexistence in a forecasting game, WP05-15

4. Matthew Hurd, Mark Salmon and Christoph Schleicher, Using Copulas to Construct Bivariate Foreign Exchange Distributions with an Application to the Sterling Exchange Rate Index (Revised), WP05-14

5. Lucio Sarno, Daniel Thornton and Giorgio Valente, The Empirical Failure of the Expectations Hypothesis of the Term Structure of Bond Yields, WP05-13

6. Lucio Sarno, Ashoka Mody and Mark Taylor, A Cross-Country Financial Accelorator: Evidence from North America and Europe, WP05-12

7. Lucio Sarno, Towards a Solution to the Puzzles in Exchange Rate Economics: Where Do We Stand?, WP05-11

8. James Hodder and Jens Carsten Jackwerth, Incentive Contracts and Hedge Fund Management, WP05-10

9. James Hodder and Jens Carsten Jackwerth, Employee Stock Options: Much More Valuable Than You Thought, WP05-09 
10. Gordon Gemmill, Soosung Hwang and Mark Salmon, Performance Measurement with Loss Aversion, WP05-08

11. George Constantinides, Jens Carsten Jackwerth and Stylianos Perrakis, Mispricing of S\&P 500 Index Options, WP05-07

12. Elisa Luciano and Wim Schoutens, A Multivariate Jump-Driven Financial Asset Model, WP0506

13. Cees Diks and Florian Wagener, Equivalence and bifurcations of finite order stochastic processes, WP05-05

14. Devraj Basu and Alexander Stremme, CAY Revisited: Can Optimal Scaling Resurrect the (C)CAPM?, WP05-04

15. Ginwestra Bianconi and Matteo Marsili, Emergence of large cliques in random scale-free networks, WP05-03

16. Simone Alfarano, Thomas Lux and Friedrich Wagner, Time-Variation of Higher Moments in a Financial Market with Heterogeneous Agents: An Analytical Approach, WP05-02

17. Abhay Abhayankar, Devraj Basu and Alexander Stremme, Portfolio Efficiency and Discount Factor Bounds with Conditioning Information: A Unified Approach, WP05-01

\section{4}

1. Xiaohong Chen, Yanqin Fan and Andrew Patton, Simple Tests for Models of Dependence Between Multiple Financial Time Series, with Applications to U.S. Equity Returns and Exchange Rates, WP04-19

2. Valentina Corradi and Walter Distaso, Testing for One-Factor Models versus Stochastic Volatility Models, WP04-18

3. Valentina Corradi and Walter Distaso, Estimating and Testing Sochastic Volatility Models using Realized Measures, WP04-17

4. Valentina Corradi and Norman Swanson, Predictive Density Accuracy Tests, WP04-16

5. Roel Oomen, Properties of Bias Corrected Realized Variance Under Alternative Sampling Schemes, WP04-15

6. Roel Oomen, Properties of Realized Variance for a Pure Jump Process: Calendar Time Sampling versus Business Time Sampling, WP04-14

7. Richard Clarida, Lucio Sarno, Mark Taylor and Giorgio Valente, The Role of Asymmetries and Regime Shifts in the Term Structure of Interest Rates, WP04-13

8. Lucio Sarno, Daniel Thornton and Giorgio Valente, Federal Funds Rate Prediction, WP04-12

9. Lucio Sarno and Giorgio Valente, Modeling and Forecasting Stock Returns: Exploiting the Futures Market, Regime Shifts and International Spillovers, WP04-11

10. Lucio Sarno and Giorgio Valente, Empirical Exchange Rate Models and Currency Risk: Some Evidence from Density Forecasts, WP04-10

11. Ilias Tsiakas, Periodic Stochastic Volatility and Fat Tails, WP04-09

12. Ilias Tsiakas, Is Seasonal Heteroscedasticity Real? An International Perspective, WP04-08

13. Damin Challet, Andrea De Martino, Matteo Marsili and Isaac Castillo, Minority games with finite score memory, WP04-07

14. Basel Awartani, Valentina Corradi and Walter Distaso, Testing and Modelling Market Microstructure Effects with an Application to the Dow Jones Industrial Average, WP04-06

15. Andrew Patton and Allan Timmermann, Properties of Optimal Forecasts under Asymmetric Loss and Nonlinearity, WP04-05

16. Andrew Patton, Modelling Asymmetric Exchange Rate Dependence, WP04-04

17. Alessio Sancetta, Decoupling and Convergence to Independence with Applications to Functional Limit Theorems, WP04-03

18. Alessio Sancetta, Copula Based Monte Carlo Integration in Financial Problems, WP04-02

19. Abhay Abhayankar, Lucio Sarno and Giorgio Valente, Exchange Rates and Fundamentals: Evidence on the Economic Value of Predictability, WP04-01

\section{2}

1. Paolo Zaffaroni, Gaussian inference on Certain Long-Range Dependent Volatility Models, WP02-12

2. Paolo Zaffaroni, Aggregation and Memory of Models of Changing Volatility, WP02-11

3. Jerry Coakley, Ana-Maria Fuertes and Andrew Wood, Reinterpreting the Real Exchange Rate - Yield Diffential Nexus, WP02-10 
4. Gordon Gemmill and Dylan Thomas, Noise Training, Costly Arbitrage and Asset Prices: evidence from closed-end funds, WP02-09

5. Gordon Gemmill, Testing Merton's Model for Credit Spreads on Zero-Coupon Bonds, WP0208

6. George Christodoulakis and Steve Satchell, On th Evolution of Global Style Factors in the MSCI Universe of Assets, WP02-07

7. George Christodoulakis, Sharp Style Analysis in the MSCI Sector Portfolios: A Monte Caro Integration Approach, WP02-06

8. George Christodoulakis, Generating Composite Volatility Forecasts with Random Factor Betas, WP02-05

9. Claudia Riveiro and Nick Webber, Valuing Path Dependent Options in the Variance-Gamma Model by Monte Carlo with a Gamma Bridge, WP02-04

10. Christian Pedersen and Soosung Hwang, On Empirical Risk Measurement with Asymmetric Returns Data, WP02-03

11. Roy Batchelor and Ismail Orgakcioglu, Event-related GARCH: the impact of stock dividends in Turkey, WP02-02

12. George Albanis and Roy Batchelor, Combining Heterogeneous Classifiers for Stock Selection, WP02-01

\section{1}

1. Soosung Hwang and Steve Satchell, GARCH Model with Cross-sectional Volatility; GARCHX Models, WP01-16

2. Soosung Hwang and Steve Satchell, Tracking Error: Ex-Ante versus Ex-Post Measures, WP01-15

3. Soosung Hwang and Steve Satchell, The Asset Allocation Decision in a Loss Aversion World, WP01-14

4. Soosung Hwang and Mark Salmon, An Analysis of Performance Measures Using Copulae, WP01-13

5. Soosung Hwang and Mark Salmon, A New Measure of Herding and Empirical Evidence, WP01-12

6. Richard Lewin and Steve Satchell, The Derivation of New Model of Equity Duration, WP0111

7. Massimiliano Marcellino and Mark Salmon, Robust Decision Theory and the Lucas Critique, WP01-10

8. Jerry Coakley, Ana-Maria Fuertes and Maria-Teresa Perez, Numerical Issues in Threshold Autoregressive Modelling of Time Series, WP01-09

9. Jerry Coakley, Ana-Maria Fuertes and Ron Smith, Small Sample Properties of Panel Timeseries Estimators with I(1) Errors, WP01-08

10. Jerry Coakley and Ana-Maria Fuertes, The Felsdtein-Horioka Puzzle is Not as Bad as You Think, WP01-07

11. Jerry Coakley and Ana-Maria Fuertes, Rethinking the Forward Premium Puzzle in a Nonlinear Framework, WP01-06

12. George Christodoulakis, Co-Volatility and Correlation Clustering: A Multivariate Correlated ARCH Framework, WP01-05

13. Frank Critchley, Paul Marriott and Mark Salmon, On Preferred Point Geometry in Statistics, WP01-04

14. Eric Bouyé and Nicolas Gaussel and Mark Salmon, Investigating Dynamic Dependence Using Copulae, WP01-03

15. Eric Bouyé, Multivariate Extremes at Work for Portfolio Risk Measurement, WP01-02

16. Erick Bouyé, Vado Durrleman, Ashkan Nikeghbali, Gael Riboulet and Thierry Roncalli, Copulas: an Open Field for Risk Management, WP01-01

\section{0}

1. Soosung Hwang and Steve Satchell, Valuing Information Using Utility Functions, WP00-06

2. Soosung Hwang, Properties of Cross-sectional Volatility, WP00-05

3. Soosung Hwang and Steve Satchell, Calculating the Miss-specification in Beta from Using a Proxy for the Market Portfolio, WP00-04

4. Laun Middleton and Stephen Satchell, Deriving the APT when the Number of Factors is Unknown, WP00-03 
5. George A. Christodoulakis and Steve Satchell, Evolving Systems of Financial Returns: AutoRegressive Conditional Beta, WP00-02

6. Christian S. Pedersen and Stephen Satchell, Evaluating the Performance of Nearest Neighbour Algorithms when Forecasting US Industry Returns, WP00-01

\section{9}

1. Yin-Wong Cheung, Menzie Chinn and Ian Marsh, How do UK-Based Foreign Exchange Dealers Think Their Market Operates?, WP99-21

2. Soosung Hwang, John Knight and Stephen Satchell, Forecasting Volatility using LINEX Loss Functions, WP99-20

3. Soosung Hwang and Steve Satchell, Improved Testing for the Efficiency of Asset Pricing Theories in Linear Factor Models, WP99-19

4. Soosung Hwang and Stephen Satchell, The Disappearance of Style in the US Equity Market, WP99-18

5. Soosung Hwang and Stephen Satchell, Modelling Emerging Market Risk Premia Using Higher Moments, WP99-17

6. Soosung Hwang and Stephen Satchell, Market Risk and the Concept of Fundamental Volatility: Measuring Volatility Across Asset and Derivative Markets and Testing for the Impact of Derivatives Markets on Financial Markets, WP99-16

7. Soosung Hwang, The Effects of Systematic Sampling and Temporal Aggregation on Discrete Time Long Memory Processes and their Finite Sample Properties, WP99-15

8. Ronald MacDonald and Ian Marsh, Currency Spillovers and Tri-Polarity: a Simultaneous Model of the US Dollar, German Mark and Japanese Yen, WP99-14

9. Robert Hillman, Forecasting Inflation with a Non-linear Output Gap Model, WP99-13

10. Robert Hillman and Mark Salmon, From Market Micro-structure to Macro Fundamentals: is there Predictability in the Dollar-Deutsche Mark Exchange Rate?, WP99-12

11. Renzo Avesani, Giampiero Gallo and Mark Salmon, On the Evolution of Credibility and Flexible Exchange Rate Target Zones, WP99-11

12. Paul Marriott and Mark Salmon, An Introduction to Differential Geometry in Econometrics, WP99-10

13. Mark Dixon, Anthony Ledford and Paul Marriott, Finite Sample Inference for Extreme Value Distributions, WP99-09

14. Ian Marsh and David Power, A Panel-Based Investigation into the Relationship Between Stock Prices and Dividends, WP99-08

15. Ian Marsh, An Analysis of the Performance of European Foreign Exchange Forecasters, WP99-07

16. Frank Critchley, Paul Marriott and Mark Salmon, An Elementary Account of Amari's Expected Geometry, WP99-06

17. Demos Tambakis and Anne-Sophie Van Royen, Bootstrap Predictability of Daily Exchange Rates in ARMA Models, WP99-05

18. Christopher Neely and Paul Weller, Technical Analysis and Central Bank Intervention, WP9904

19. Christopher Neely and Paul Weller, Predictability in International Asset Returns: A Reexamination, WP99-03

20. Christopher Neely and Paul Weller, Intraday Technical Trading in the Foreign Exchange Market, WP99-02

21. Anthony Hall, Soosung Hwang and Stephen Satchell, Using Bayesian Variable Selection Methods to Choose Style Factors in Global Stock Return Models, WP99-01

\section{8}

1. Soosung Hwang and Stephen Satchell, Implied Volatility Forecasting: A Compaison of Different Procedures Including Fractionally Integrated Models with Applications to UK Equity Options, WP98-05

2. Roy Batchelor and David Peel, Rationality Testing under Asymmetric Loss, WP98-04

3. Roy Batchelor, Forecasting T-Bill Yields: Accuracy versus Profitability, WP98-03

4. Adam Kurpiel and Thierry Roncalli, Option Hedging with Stochastic Volatility, WP98-02

5. Adam Kurpiel and Thierry Roncalli, Hopscotch Methods for Two State Financial Models, WP98-01 